\title{
Universiteit
}

Leiden

The Netherlands

\section{Marked differences in tissue-specific expression of chitinases in mouse and man}

Boot, R.G.; Bussink, A.P.; Verhoek, M.; Boer, P.A.J. de; Moorman, A.F.M.; Aerts, J.M.F.G.

\section{Citation}

Boot, R. G., Bussink, A. P., Verhoek, M., Boer, P. A. J. de, Moorman, A. F. M., \& Aerts, J. M. F. G. (2005). Marked differences in tissue-specific expression of chitinases in mouse and man. Journal Of Histochemistry And Cytochemistry, 53(10), 1283-1292. doi:10.1369/jhc.4A6547.2005

Version: $\quad$ Not Applicable (or Unknown)

License: $\quad$ Leiden University Non-exclusive license

Downloaded from: https://hdl.handle.net/1887/69047

Note: To cite this publication please use the final published version (if applicable). 


\title{
Marked Differences in Tissue-specific Expression of Chitinases in Mouse and Man
}

\author{
Rolf G. Boot, Anton P. Bussink, Marri Verhoek, Piet A.J. de Boer, Antoon F.M. Moorman, \\ and Johannes M.F.G. Aerts \\ Department of Biochemistry (RGB,APB,MV,JMFGA), and Department of Anatomy \& Embryology (PAJdB,AFMM), University \\ of Amsterdam Academic Medical Center, Amsterdam, The Netherlands
}

\begin{abstract}
SUMMARY Two distinct chitinases have been identified in mammals: a phagocyte-specific enzyme named chitotriosidase and an acidic mammalian chitinase (AMCase) expressed in the lungs and gastrointestinal tract. Increased expression of both chitinases has been observed in different pathological conditions: chitotriosidase in lysosomal lipid storage disorders like Gaucher disease and AMCase in asthmatic lung disease. Recently, it was reported that AMCase activity is involved in the pathogenesis of asthma in an induced mouse model. Inhibition of chitinase activity was found to alleviate the inflammation-driven pathology. We studied the tissue-specific expression of both chitinases in mice and compared it to the situation in man. In both species AMCase is expressed in alveolar macrophages and in the gastrointestinal tract. In mice, chitotriosidase is expressed only in the gastrointestinal tract, the tongue, fore-stomach, and Paneth cells in the small intestine, whereas in man the enzyme is expressed exclusively by professional phagocytes. This species difference seems to be mediated by distinct promoter usage. In conclusion, the pattern of expression of chitinases in the lung differs between mouse and man. The implications for the development of anti-asthma drugs with chitinases as targets are discussed.
\end{abstract}

(J Histochem Cytochem 53:1283-1292, 2005)

\author{
KEY WORDS \\ chitinases \\ acidic mammalian chitinase \\ chitotriosidase \\ gastrointestinal tract \\ macrophage \\ in situ hybridization
}

RECENTLY, mammalian chitinases have attracted considerable attention. Of particular interest is the claim that activity of an endogenous lung chitinase plays a key role in the pathogenesis of asthma in an induced mouse model (Zhu et al. 2004). The existence of endogenous mammalian chitinases has been relatively recently documented. The finding of a profound chitotriosidase activity in plasma of Gaucher patients formed the basis for subsequent identification and characterization of a human phagocyte-specific chitinase named chitotriosidase (Hollak et al. 1994; Boot et al. 1995; Renkema et al. 1995,1998). Human tissue macrophages are able to produce large amounts of chitotriosidase upon appropriate stimulation, such as the massive lipid accumulation that occurs in macrophages of Gaucher

Correspondence to: Rolf G. Boot, Department of Biochemistry, University of Amsterdam Academic Medical Center, PO Box 22700, 1100 DE, Amsterdam, The Netherlands. E-mail: r.g.boot@amc.uva.nl Received for publication October 11, 2004; accepted April 14, 2005 [DOI: 10.1369/jhc.4A6547.2005]. patients. Macrophages secrete a 50-kDa active enzyme, which consists of a catalytic domain and a C-terminal chitin-binding domain separated by a hinge region (Renkema et al. 1997; Tjoelker et al. 2000). Chitotriosidase is not expressed in other cell types with the exception of progenitors of neutrophilic granulocytes. These cells synthesize $50-\mathrm{kDa}$ chitotriosidase that is stored in their specific granules (Boot et al. 1995; Boussac and Garin 2000).

The physiological function of chitotriosidase is not completely resolved. Its phagocyte-specific expression suggests a role in innate immunity. Highly homologous plant chitinases are prominent "pathogenesisrelated proteins" that are induced following attack by pathogens and take part in the defense against chitincontaining fungi (Schlumbaum et al. 1986; Sahai and Manocha 1993). A similar role for chitotriosidase in the human innate immune system is indicated by our observation that recombinant chitotriosidase is fungistatic in mice models of systemic fungal infections (Stevens et al. 2000; van Eijk MC, Boot RG, and Aerts 
JMFG, unpublished data). Interestingly, $\sim 1$ in 20 individuals is completely deficient in chitotriosidase activity due to a 24-bp duplication in the gene that occurs panethnically (Hollak et al. 1994; Boot et al. 1998). This high prevalence of deficiency suggests that human chitotriosidase either no longer fulfills an important function under normal conditions or that other mechanisms may compensate for the lack of a functional chitinase (Boot et al. 1998). The occurrence of deficiency in chitotriosidase is associated with susceptibility to infection with Wuchereria bancrofti, a filarial parasite whose microfilarial sheath contains chitin (Choi et al. 2001). In search of compensatory chitinases in mammals we identified and characterized a second mammalian chitinase named acidic mammalian chitinase (AMCase) (Boot et al. 2001). This $50-\mathrm{kDa}$ enzyme is structurally highly related to chitotriosidase.

AMCase occurs in the gastrointestinal tract and lungs of rodents and man. Suzuki et al. (2002) also detected AMCase mRNA in exocrine cells of the serous type of mice. Unlike human chitotriosidase, AMCase has an acidic $\mathrm{pH}$ optimum and is very acid stable (Boot et al. 2001). The enzyme appears to be adapted to function in the extreme stomach environment, where it may fulfill a role in defense and/or digestion of chitin-containing organisms.

In the lung of mice, but not of man, AMCase is the sole detectable endogenous chitinase. In a number of recent reports the mRNA expression of AMCase in the lung of mice was shown to be highly regulated (Sandler et al. 2003; Xu et al. 2003; Zhu et al. 2004; Zimmermann et al. 2004). Intravenous injection of Schistosoma mansoni eggs was found to cause massive expression of AMCase in the lung of wild-type mice and animals with an exaggerated Th2 response that is dominated by the cytokines IL4 and IL13. This induction did not occur in mice with an exaggerated Th1 response or IL13-knockout mice (Sandler et al. 2003). Zimmermann et al. (2004) reported highly induced AMCase mRNA levels in mouse models of experimental asthma induced either by ovalbumin or by Aspergillus fumigatus antigen. This induction was mediated by the STAT6 signaling pathway, again suggesting a role for IL4 or IL13 (Zimmermann et al. 2004). Very recently it was shown for an aeroallergen asthma mouse model that AMCase is induced in the lung via a Th2specific, IL13-mediated pathway (Zhu et al. 2004). Interestingly, AMCase activity appeared instrumental for the pathogenesis of asthma. Inhibition of AMCase, either by a specific antibody or the specific chitinase inhibitor allosamidin, alleviated the Th2-mediated inflammatory damage that occurs in asthma (Zhu et al. 2004). It has been suggested that inhibition of chitinase activity may render an attractive new therapy for asthma (Couzin 2004; Zhu et al. 2004).

So far, all attention in studies with mouse models has been focused on AMCase, whereas chitotriosidase, the dominant chitinase in man, has received little attention. We investigated the expression of chitotriosidase and AMCase in mice in more detail. We show here that remarkable differences between man and mouse exist regarding cell type and tissue-specific expression of chitinases. Comparison of promoter sequences of the human and murine chitinase genes helps to explain the species-specific tissue expression of chitinases. The implications for extrapolating observations on chitinase made in mouse models to the human situation are discussed.

\section{Materials and Methods}

\section{Enzyme Assays}

Chitinase enzyme activity was determined with the fluorogenic substrates 4MU-chitobiose (4-methylumbelliferyl $\beta-\mathrm{D}-\mathrm{N}, \mathrm{N}^{\prime}$-diacetylchitobiose; Sigma, St Louis, MO) and 4MUchitotriose (4-methylumbelliferyl $\beta-\mathrm{D}-\mathrm{N}, \mathrm{N}^{\prime}, \mathrm{N}^{\prime \prime}$-triacetylchitotriose; Sigma). Assay mixtures contained $0.027 \mathrm{mM}$ substrate and $1 \mathrm{mg} / \mathrm{ml}$ of bovine serum albumin in McIlvaine buffer (100 mM citric acid, $200 \mathrm{mM}$ sodium phosphate) at the indicated $\mathrm{pH}$. The standard enzyme activity assay for human chitotriosidase with 4MU-chitotriose substrate was performed at $\mathrm{pH}$ 5.2, as previously described (Hollak et al. 1994). The standard AMCase enzyme activity assays with 4MU-chitobiose substrate were performed at $\mathrm{pH} 4.5$.

\section{RNA Isolation, Northern Blot, and RNA Master Blot Analysis}

Total spleen RNA was isolated using the RNAzol B (Biosolve; Barneveld, The Netherlands) RNA isolation kit according to the manufacturer's instructions. For Northern blot analysis, $15-\mu \mathrm{g}$ samples of total RNA were run in $10 \mathrm{mM}$ Hepes ( $\mathrm{pH} 7.5$ ), $6 \%$ formaldehyde-agarose gels, transferred to Hybond N nylon membranes (Amersham; Buckinghamshire, UK) by the capillary method, and immobilized by UV cross-linking. Full-length mouse chitotriosidase cDNA was used as probe. Human RNA Master Blots (Clontech; Palo Alto, CA) were used to examine the tissue distribution of the human chitotriosidase transcript according to the instructions of the manufacturer, using the full-length human chitotriosidase cDNA as probe. The probes were radiolabeled with ${ }^{32} \mathrm{P}$ using the random priming method. Hybridization conditions were exactly as previously described (Boot et al. 1995).

\section{Isoelectric Focusing}

The native isoelectric point of chitinases was determined by flatbed isoelectric focusing in granulated Ultrodex gels (Pharmacia; Uppsala, Sweden) as described (Renkema et al. 1995).

\section{CDNA Cloning of the Mouse Chitotriosidase}

Reverse transcription-polymerase chain reaction (RT-PCR) fragments were generated from mouse pooled tissue total RNA using degenerate oligonucleotides, as described (Boot et al. 1995). Obtained fragments were cloned in pGEM-T (Promega; Madison, WI) and sequenced. A comparison with 
the GenBank mouse expressed sequence tag (EST) database using the basic local alignment search tool (BLAST) at the National Center for Biotechnology Information showed that several EST clones matched the mouse chitotriosidase cDNA sequence. Full-length mouse chitotriosidase cDNA was generated using specific primers based on these deposited sequences. The nucleotide sequence of two independent clones from the PCR were sequenced from both strands by the procedure of Sanger using fluorescent nucleotides on an Applied Biosystems (ABI; Foster City, CA) 377A automated DNA sequencer following ABI protocols.

\section{Transient Expression in COS-1 Cells}

Transient expression of the various cDNAs in COS- 1 cells was performed to generate recombinant enzyme exactly as described previously (Boot et al. 1995).

\section{Tissue Processing}

More detailed practical protocols for fixation, paraffin embedding, mounting, and sectioning have been described (Moorman et al. 2000). In short, tissues removed from a FVB mouse were fixed for $4 \mathrm{hr}$ to overnight in freshly prepared $4 \%$ formaldehyde in PBS by rocking at 4C. The tissues were then dehydrated in a graded ethanol series, paraffin embedded, cut into sections, and carefully mounted on aminoalkylsilane-coated slides to prevent loss of the tissue sections during the extensive treatments of the in situ hybridization (ISH) procedure.

\section{RNA Probes and Probe Specification}

Digoxigenin-labeled probes were made according to the manufacturer's specifications (Roche; Mannheim, Germany). RNA probes complementary to the full-length mouse mRNAs encoding chitotriosidase, AMCase, GOB-5 or calcium-activated chloride channel 3, glutamine synthase, and lysozyme $\mathrm{P}$ were used. Due to the high identity, the lysozyme probe under the conditions used also detects the lysozyme M mRNA.

\section{Non-radioactive ISH}

Non-radioactive ISH was performed as described (Moorman et al. 2001). In short, after removal of paraffin, sections were pretreated by proteolytic digestion for 5-15 $\mathrm{min}$ at $37 \mathrm{C}$ with $20 \mu \mathrm{g} / \mathrm{ml}$ proteinase $\mathrm{K}$ dissolved in PBS, followed by a 5 -min rinse in $0.2 \%$ glycine/PBS, and two rinses of 5 $\mathrm{min}$ in PBS. Sections were then re-fixed for $20 \mathrm{~min}$ in $4 \%$ formaldehyde $/ 0.2 \%$ glutaraldehyde dissolved in PBS to ensure firm attachment of the sections to the microscope slides and washed twice in PBS for 5 min. Sections were prehybridized in hybridization mix without probe for $1 \mathrm{hr}$ at $70 \mathrm{C}$ and then hybridized overnight at 70C. The hybridization mixture was composed of 50\% formamide, $5 \times$ SSC, $1 \%$ block solution (Roche), 5 mM EDTA, 0.1\% Tween-20, 0.1\% Chaps (Sigma), $0.1 \mathrm{mg} / \mathrm{ml}$ heparin (Becton-Dickinson; Mountain View, CA), and $1 \mathrm{mg} / \mathrm{ml}$ yeast total RNA (Roche). Probe concentration was $\sim 1 \mathrm{ng} / \mu \mathrm{l}$. Approximately $6 \mu \mathrm{l}$ hybridization mix was applied to the sections, and no coverslips were used. After hybridization, sections were rinsed in $2 \times$ SSC, $\mathrm{pH} 4.5$, washed three times for $30 \mathrm{~min}$ at $65 \mathrm{C}$ in $50 \%$ for- mamide/ $2 \times \mathrm{SSC}, \mathrm{pH} 4.5$, followed by three 5 -min washes in PBST. Probe bound to the section was immunologically detected using sheep anti-digoxigenin Fab fragment covalently coupled to alkaline phosphatase and NBT/BCIP as chromogenic substrate, essentially according to the manufacturer's protocol (Roche). Sections were washed with double-distilled water, dehydrated in a graded ethanol series and xylene, and embedded in Entellan (Merck; Darmstadt, Germany).

\section{Results}

The mouse and human ortholog of the AMCase have been identified recently (Boot et al. 2001). The human AMCase gene is located on chromosome 1p13, whereas the locus of the human chitotriosidase gene is found on chromosome 1q32 (Boot et al. 1998). The mouse AMCase gene is located on chromosome 3F3, a region that is syntenic with human $1 \mathrm{p} 13$. Recently, we and others have cloned the mouse ortholog of human chitotriosidase (GenBank Accession numbers: AY536287.1 and AY458654.1, respectively).

Alignment of mouse and human chitotriosidase amino acid sequences revealed that there is an identity of $75 \%$ and a similarity of $78 \%$. To group all the known mouse and human chitinase protein family members and to determine whether this cloned sequence is the true ortholog of human chitotriosidase, multiple sequence alignments of their cDNAs, coding for the catalytic $39-\mathrm{kDa}$ domain only, were made using the Clustal X program (Thompson et al. 1997). The sequences used for this alignment are human chitotriosidase (GenBank Accession Number: U29615), human-HC gp39 (GenBank Accession Number: M80927), human-AMCase (GenBank Accession Number: AF290004), human-oviductin (GenBank Accession Number: U09550), human-YKL39 (GenBank Accession Number: U49835), mouse-BRP39 (GenBank Accession Number: X93035), mouse-YM1 (GenBank Accession Number: M94584), mouse-AMCase (GenBank Accession Number: AF290003), and mouse-oviductin (GenBank Accession Number: D32137). Grouping of these members is calculated by the method of Neighbor Joining by Saitou and Nei (Saitou and Nei 1987). This analysis showed that the cloned mouse sequence is grouped together with human chitotriosidase. It suggests that the mouse sequence is more homologous to human chitotriosidase than to any other member of the chitinase protein family, which is indicative of being orthologs of each other.

Using the Mouse Genome Server from the Mouse Genome Sequencing Consortium (at http://www. ensembl.org/Mus_musculus), we identified genomic sequences that contained the chitotriosidase gene, enabling the determination of intron-exon boundaries. The boundaries are all conserved between human and mouse chitotriosidase genes (data not shown). Moreover, it was found that the mouse chitotriosidase gene is located on chromosome 1 band E4 near the bound- 
ary with F. This region is syntenic with human chromosome 1q32. On human 1q32, only two genes of members of the chitinase protein family are located, namely, chitotriosidase (CHIT1) and HC gp39 (CHI3L1) (Jin et al. 1998). On mouse chromosome 1 band E4 the mouse BRP39 (Chi311), the mouse ortholog of HC gp39, was already identified (Jin et al. 1998). The data present on the Mouse Genome Server show that, in addition to the BRP39 gene, the mouse chitotriosidase gene is also found at this locus (see Figure 1 for overview). In addition to the syntenic chromosomal locations, the homology in intronic sequences of the mouse and human chitotriosidase genes indicate that they are orthologs.

Comparison of the properties of human and mouse chitotriosidases revealed that both enzymes show a $\mathrm{pH}$ optimum that is relatively broad and peaks around $\mathrm{pH} 6$ (Figure 2A). Like human chitotriosidase, the mouse enzyme is not acid stable in sharp contrast to the mouse AMCase, which is extremely acid stable (Figure 2B).

Northern blot analysis of different mouse tissues with the mouse chitotriosidase cDNA probe revealed highest expression in tongue and slightly less in the stomach. In other tissues, expression was not detectable (Figure 3A). The expression pattern of human chitotriosidase is remarkably different. Human chitotriosidase is expressed at relatively high levels in lymph node, bone marrow, and lung as determined with commercial tissue dot blot (Figure 3B). No expression of chitotriosidase was detectable in the human stomach. Human AMCase was found to be relatively highly expressed in the stomach and to a lesser extent

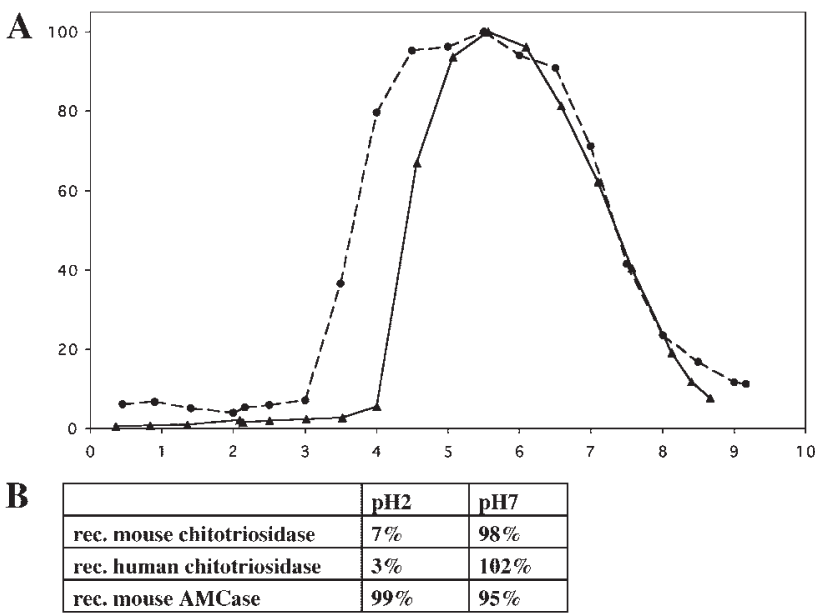

Figure 2 (A) $\mathrm{pH}$ activity profile of the different recombinant chitotriosidases. The $\mathrm{pH}$ optima were determined by monitoring enzyme activity at the indicated $\mathrm{pH}$ in Mcllvaine buffer. Purified human recombinant chitotriosidase (closed circle), purified recombinant mouse chitotriosidase (closed triangle). (B) Acid stability. Purified recombinant mouse chitotriosidase, human chitotriosidase, and mouse AMCase were preincubated for $30 \mathrm{~min}$ at the indicated $\mathrm{pH}$ in Mcllvaine buffer prior to enzyme activity measurement at the assay $\mathrm{pH}$ (see Materials and Methods). Activity prior to incubation at the indicated $\mathrm{pH}$ is defined as $100 \%$.

in the human lung using the same commercial RNA Master Blot (Boot et al. 2001). Moreover, previously it was also observed by Northern blot analysis that AMCase is expressed predominantly in the stomach, salivary glands, and lungs of mice (Boot et al. 2001).

Non-radioactive ISH was used to examine more

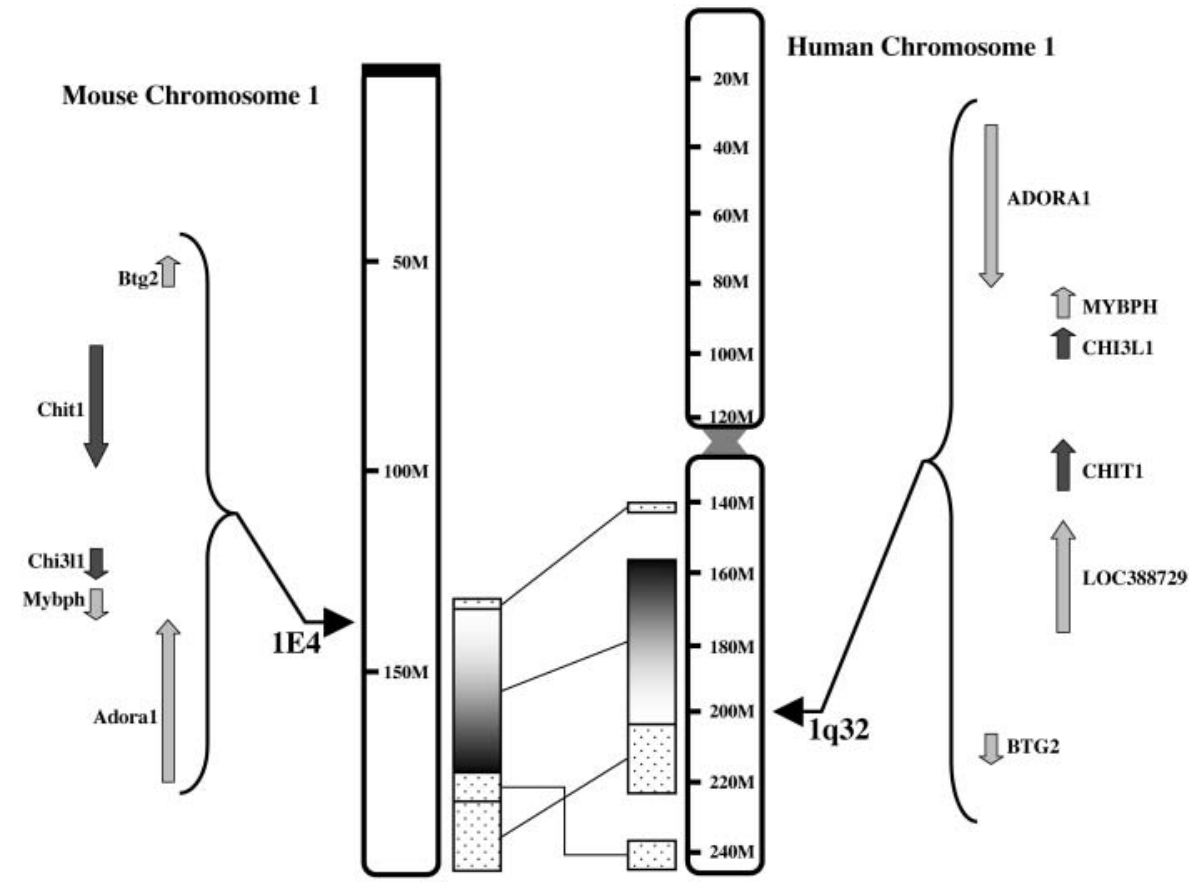

Figure 1 Schematic overview of the synteny of mouse locus $1 \mathrm{E} 4$ with human 1q32. On the left-hand side, mouse chromosome 1 with a part of locus 1E4 is indicated. On the righthand side, the human syntenic region $1 \mathrm{q} 32$ is shown. The orientation and position of a few genes in the direct neighborhood of the mouse and human chitotriosidase gene are depicted. The genes of members of the chitinase protein family are depicted in dark gray arrows, whereas the other genes are indicated with light gray arrows. The genes are BTG2, Btg2: B-cell translocation gene 2; CHIT1, Chit1: chitotriosidase; CHI3L1, Chi3l1: cartilage glycoprotein 39; $\mathrm{MYBPH}$, Mybph: myosin-binding protein $\mathrm{H}_{i}$ ADORA1, Adora1: adenosine A1 receptor; LOC388729: gene coding for the human hypothetical protein with GenBank Accession Number: XP373882. 


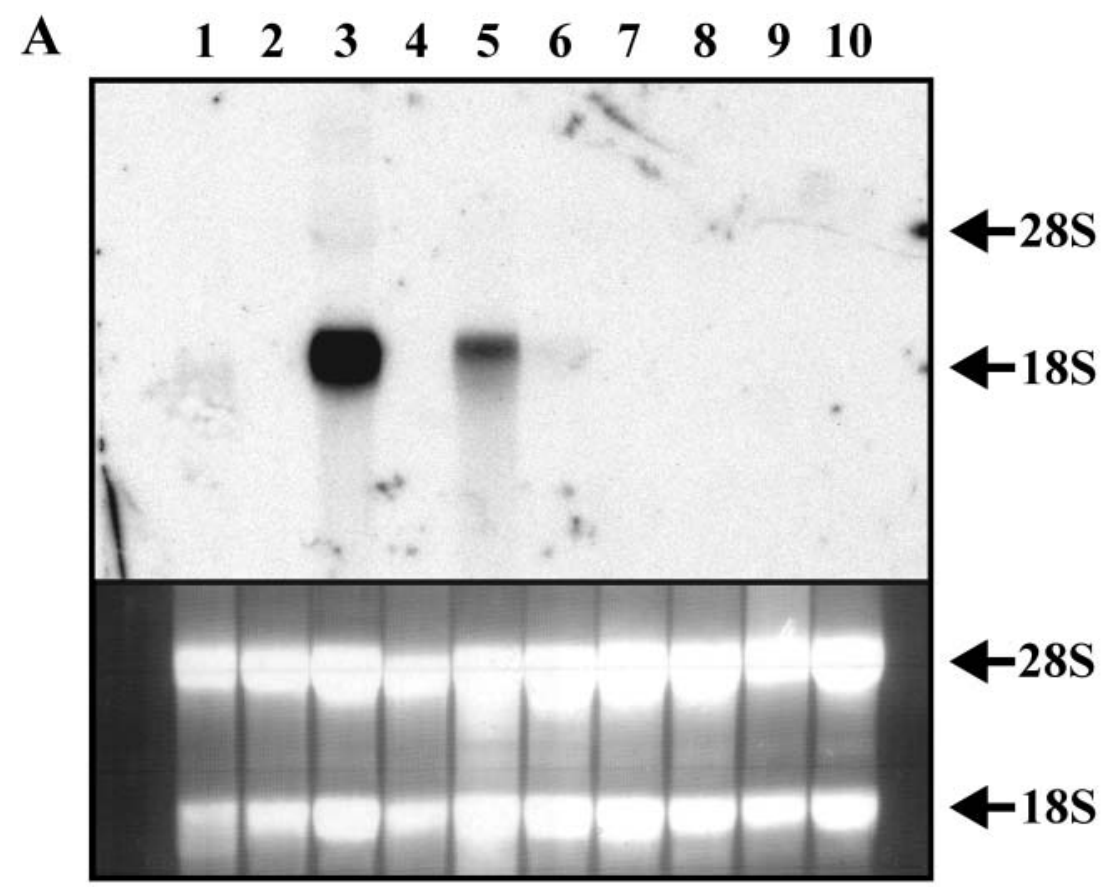

\section{B}

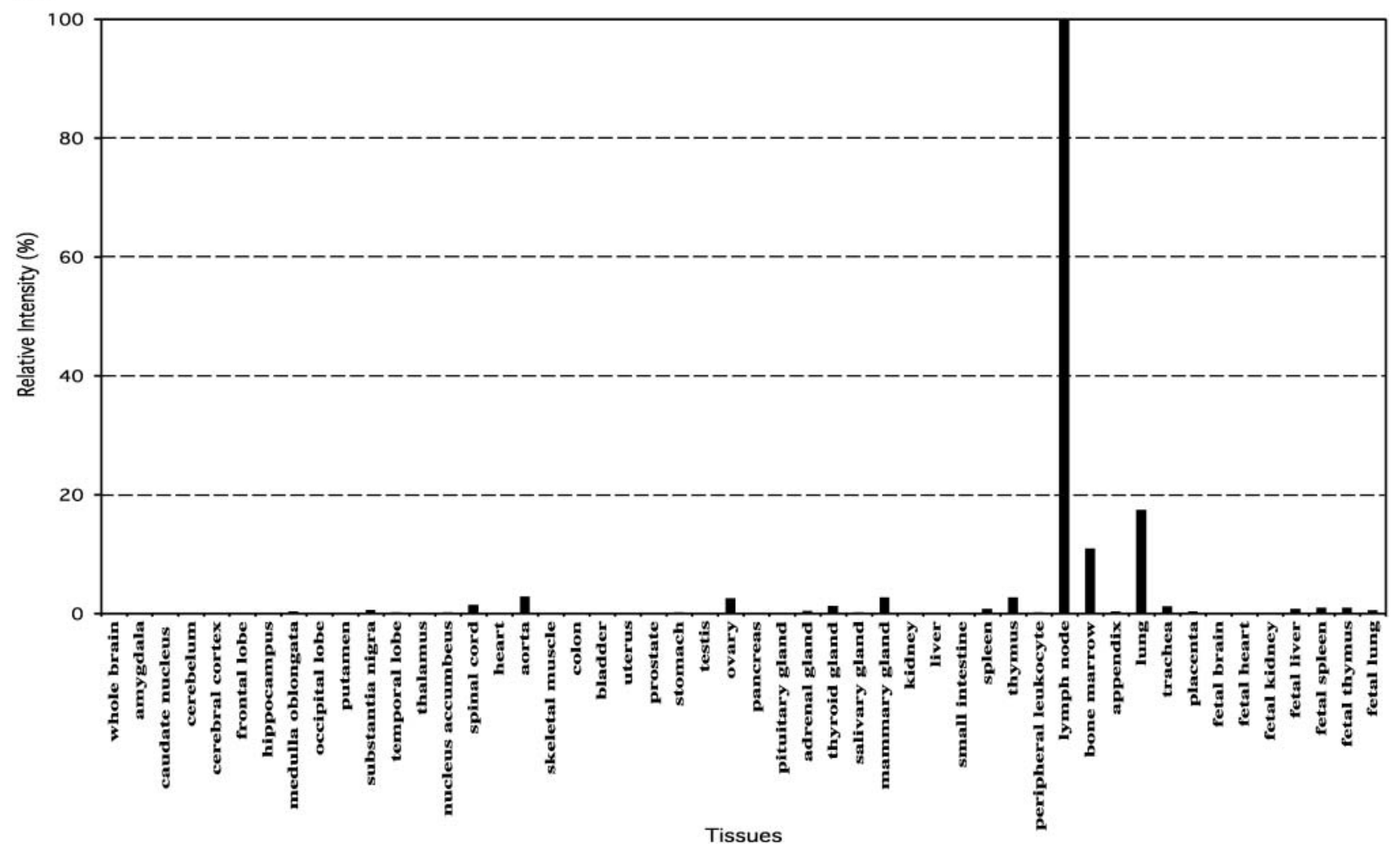

Figure 3 Tissue distribution of mouse chitotriosidase mRNA. (A) Northern blot of RNA isolated from the indicated mouse tissues. Fifteen $\mu \mathrm{g}$ total RNA was separated on an agarose gel as described in Materials and Methods. The full-length mouse chitotriosidase cDNA was used as probe. Lower part of the figure shows the ethidium bromide-stained gel as a control for RNA loading. The position of the 18S rRNA band is indicated. Lane 1, bone marrow; Lane 2, lymph node; Lane 3, tongue; Lane 4, brain; Lane 5, stomach; Lane 6, lung; Lane 7, kidney; Lane 8, liver; Lane 9, colon; Lane 10, small intestine. (B) The relative expression levels of human chitotriosidase in various tissues as determined by dot blot analysis using a RNA Master Blot (Clontech) as described under Materials and Methods. The tissue with the highest levels of chitotriosidase is defined as $100 \%$. 
closely the cellular sources of mouse chitotriosidase and mouse AMCase. As references, the expression of other genes was visualized. The genes used as reference are lysozyme $\mathrm{P}$ because of the analogy with chitinases, GOB-5, a calcium-activated chloride channel and goblet cell marker, and glutamine synthase as a positive control for expression in the stomach and liver.

Using ISH, no mRNA for chitotriosidase and AMCase was detectable in brain, colon, pancreas, liver, heart, kidney, skin, and spleen (data not shown) in agreement with the results obtained with the Northern blot analysis. The expression of chitinases in the gastrointestinal tract of mice is complex. Starting in the mouth, profound expression of both chitinases is observed. Chitotriosidase expression was mainly detected in the mucosal surface of the tongue in the stratified squamous epithelium of the papilla (Figures 4A-4E). Whereas AMCase is mainly found in the specialized minor lingual salivary glands of the serous type, the so-called glands of von Ebner (Figures 4F and 4G), in agreement with the results described (Suzuki et al. 2002; Goto et al. 2003), in the major salivary glands intense expression of AMCase was observed in the parotid gland (Figures 5A-5C), and no expression of chitotriosidase was noted (data not shown).
Moreover, unlike the situation in humans, both chitinases are highly expressed in the mouse stomach (Figures $5 \mathrm{D}-5 \mathrm{H})$. However, chitotriosidase expression is restricted to the non-glandular fore-stomach, whereas mRNA is found in the stratified squamous epithelial layer. Glutamine synthase mRNA is also found in this region of the stomach, in a cell layer just beneath that of the chitotriosidase-expressing cells (Figures 5G and $5 \mathrm{H})$. In agreement with the results of Suzuki et al. (2002) and Goto et al. (2003), we found that AMCase is expressed in the glandular portion of the stomach, at the bottom of the gastric glands in chief cells (Figures $5 \mathrm{D}$ and $5 \mathrm{E}$ ). The pyloric glands in the antrum of the stomach show no expression of the chitinases. Further down the gastrointestinal tract, in the duodenum but also in other parts of the small intestine, chitotriosidase is expressed by Paneth cells in the crypts of Lieberkühn (Figures 5I-5K). A similar expression is observed for lysozyme. We were unable to detect AMCase in the intestine.

The expression of chitinases in the lung is of particular interest. In normal human lung, chitotriosidase is prominently expressed by alveolar macrophages. In sharp contrast, we were unable to detect significant amounts of chitotriosidase mRNA in murine lung. On
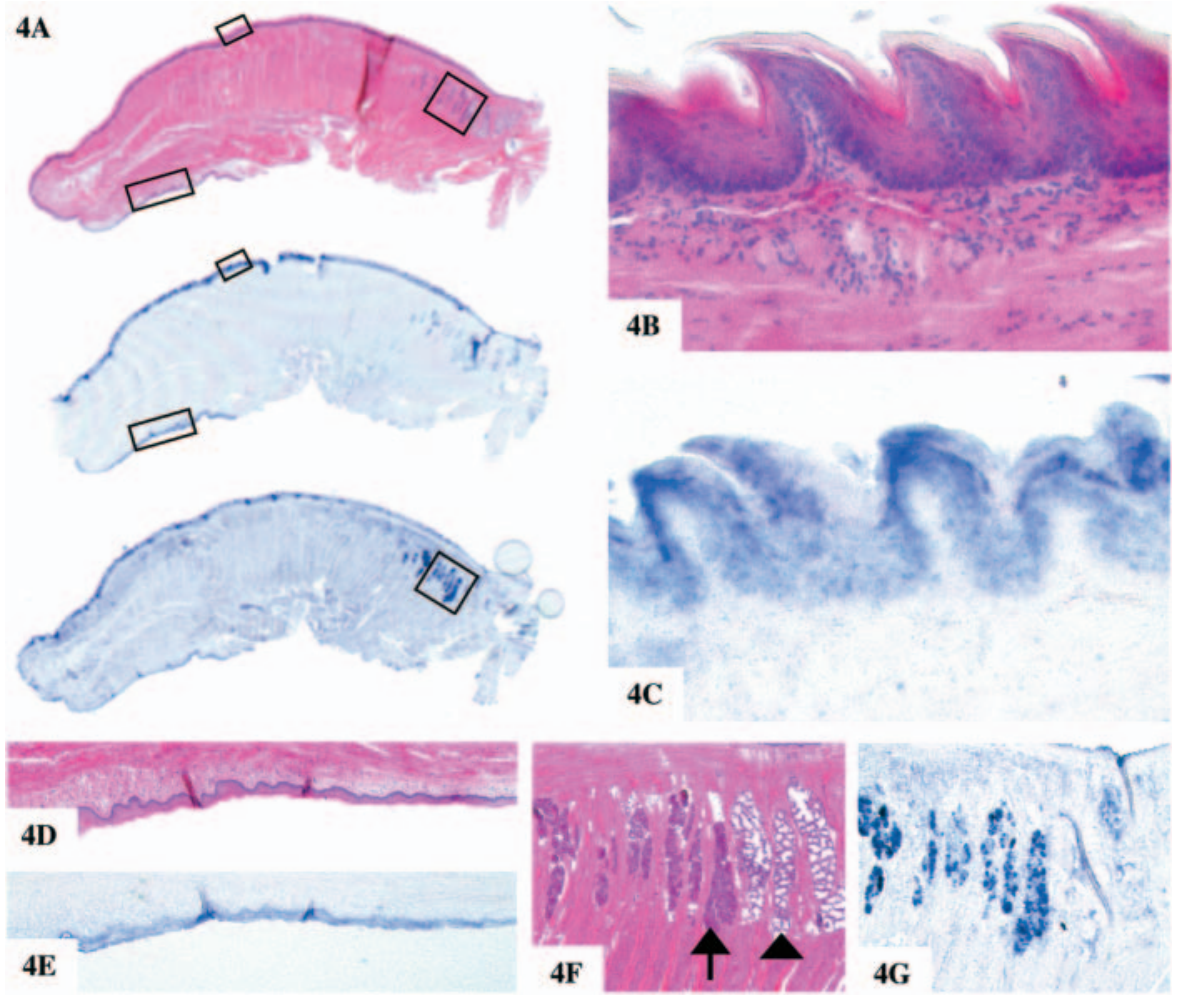

Figure 4 Non-radioactive in situ hybridization (ISH) on the tongue of normal mice. Non-radioactive ISH was performed on sections of the mouse tongue. Probe bound to the sections were immunologically detected using sheep anti-digoxigenin Fab fragment covalently coupled to alkaline phosphatase and NBT/BCIP as chromogenic substrate. The sections are not counterstained, and blue/black precipitates indicate specific mRNA expression. (A) Overview of the whole tongue. Upper serial section is stained with hematoxylin-azophlochsin, middle section shows expression of chitotriosidase, and lower section shows expression of AMCase. (B) Close-up of hematoxylin-azophlochsin-stained upper surface of the tongue with the filiform papillae (see upper rectangle, overview in A). Original magnification $\times 400$. (C) Close-up of the upper surface of the tongue showing expression of chitotriosidase in the stratified squamous epithelium (see upper rectangle, overview in A). Original magnification $\times 400$. (D) Close-up of the hematoxylin-azophlochsin-stained lower surface of the tongue (see lower rectangle, overview in A). Original magnification $\times 200$. (E) Close-up of the same region as in (D) showing expression of chitotriosidase in the stratified squamous epithelium. Original magnification $\times 200$. (F) Close-up of the minor lingual salivary glands (see right-hand rectangle, overview in A). The arrow indicates the serous type glands (von Ebner's glands), whereas the arrowhead indicates the mucous type of the lingual salivary glands. Original magnification $\times 200$. (G) Close-up of the same region as in $(F)$ showing expression of AMCase in the lingual gland of the serous type, the glands of von Ebner. Original magnification $\times 200$. 
Figure 5 Non-radioactive ISH on the gastrointestinal tract of normal mice. Non-radioactive ISH was performed on sections containing different tissues of the gastrointestinal tract. Probe bound to the sections were immunologically detected using sheep antidigoxigenin Fab fragment covalently coupled to alkaline phosphatase and NBT/BCIP as chromogenic substrate. The sections are not counterstained, and blue/black precipitates indicate specific mRNA expression. (A) Overview of the major salivary glands with specific AMCase expression in the parotid gland (arrow). (B) Serial section of the salivary glands stained with hematoxylin-azophlochsin. (C) Close-up of a part of the parotid gland (arrow from B). Original magnification $\times 100$ stained with hematoxylin-azophlochsin. (D) Overview of the whole stomach with specific expression of AMCase in the glandular portion of the stomach (arrows). (E) Close-up of the glandular portion of the stomach with strong expression of AMCase at the bottom of the gastric glands in chief cells. Original magnification $\times 200$. (F) Overview of the whole stomach with specific expression of chitotriosidase in the non-glandular fore-stomach (arrow). (G) Close-up of the fore-stomach with strong expression of chitotriosidase in the stratified squamous epithelial layer. Original magnification $\times 200$. (H) Same region and magnification with expression of glutamine synthase in a cell layer just beneath in the stratified squamous ephithelial layer. Original magnification $\times 200$. (I) Expression of lysozyme $P$ in by Paneth cells in the crypts of Lieberkühn in the ileum (arrow). Original magnification $\times 50$. (J) Serial section of the ileum with specific expression of chitotriosidase in the same Paneth cells (arrow). (K) Close-up of the intestinal wall showing expression of chitotriosidase in Paneth cells (arrow). Original magnification $\times 200$. (L) Close-up of an intestinal villus with specific expression of GOB-5 (arrow), which specifically stains goblet cells in the intestine. Original magnification $\times 200$.
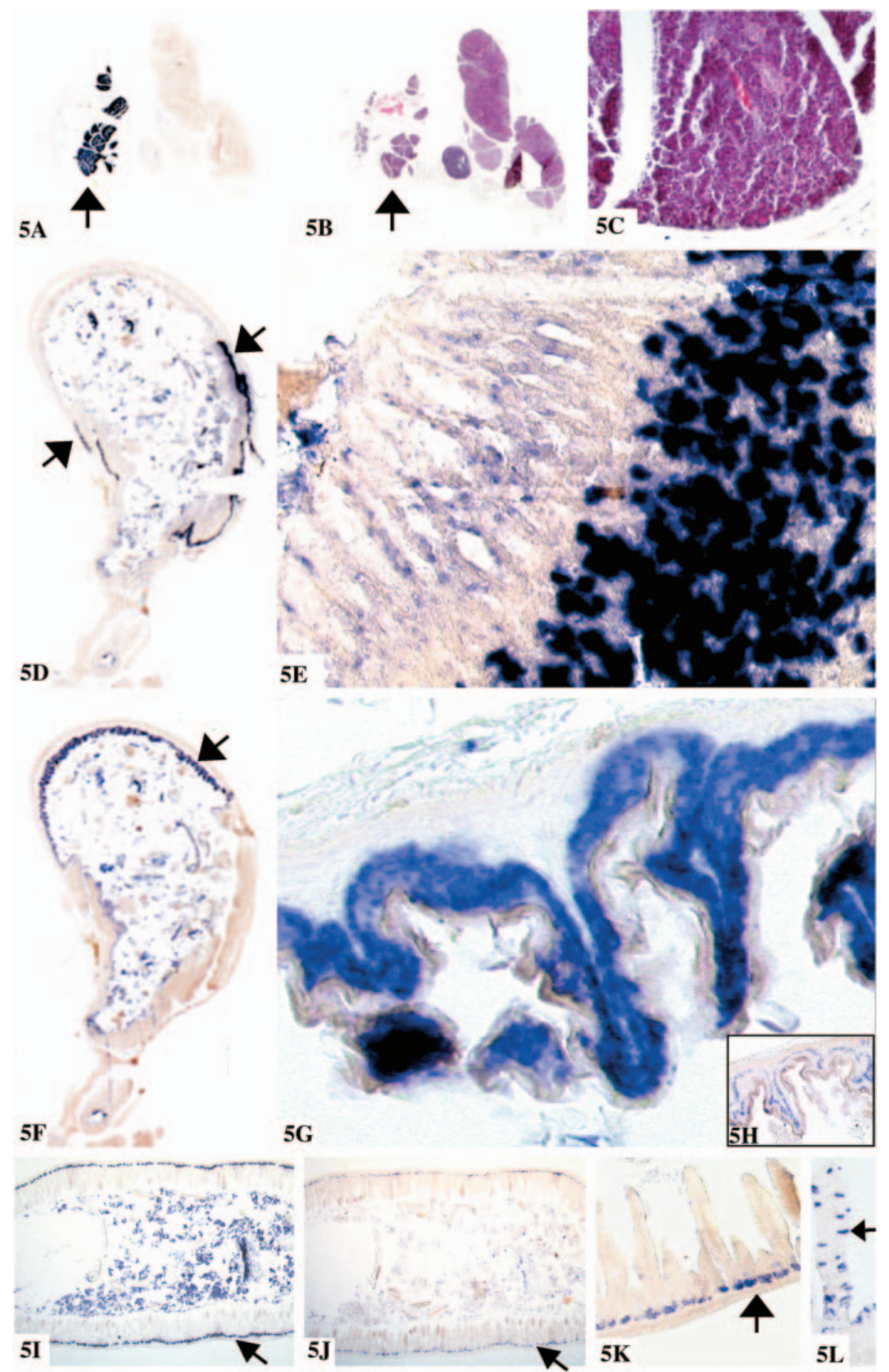

5L the other hand, AMCase mRNA is expressed by alveolar macrophages in the mouse (Figure 6).

To rule out mice strain-related effects as the basis for the observed differences in chitotriosidase expression, the activity of chitinases was measured in various relevant tissues (lung, liver, spleen, stomach, several parts of the intestine, kidney, salivary glands, tongue, and blood) from male FVB and C57BL/6 mice at dif- ferent $\mathrm{pHs}$. The relative distribution of activities was identical for both mice strains at all $\mathrm{pHs}$ measured, clearly indicating that the pattern of chitinase expression in these different mouse strains is preserved. However, it was noticed that enzyme levels were $\sim 3$-fold higher in FVB tissues compared with the corresponding tissues from C57BL/6 mice.

The remarkable difference in expression of mouse 


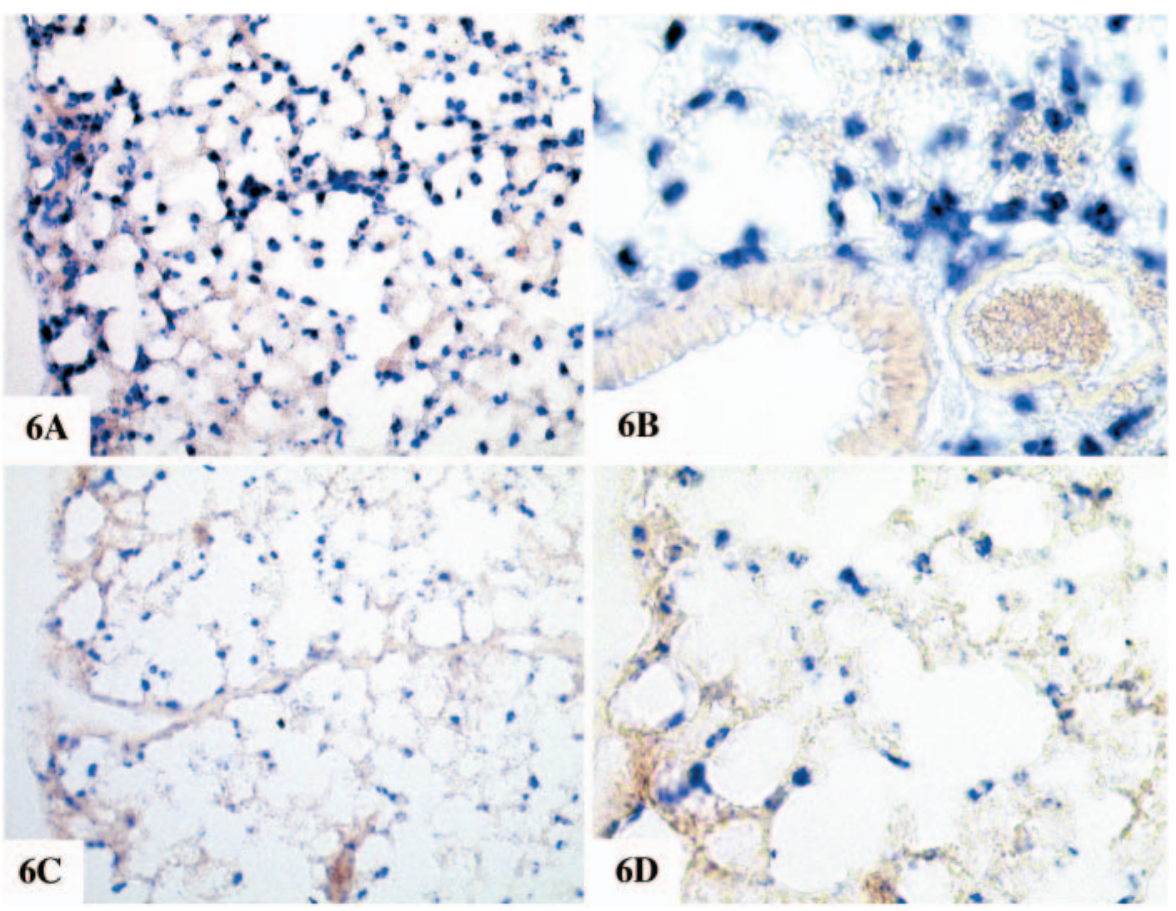

Figure 6 Non-radioactive ISH on mouse lung. Non-radioactive ISH was performed as described in Materials and Methods. Probe bound to the sections were immunologically detected using sheep anti-digoxigenin Fab fragment covalently coupled to alkaline phosphatase and NBT/BCIP as chromogenic substrate. The sections are not counterstained, and blue precipitates indicate specific mRNA expression. In the mouse lung, strong mRNA expression could be detected for lysozyme $M(\mathbf{A}, \mathbf{B})$. Strong expression in fewer cells could be detected for AMCase in the mouse lung $(C, D)$. Original magnification $(A, C) \times 200$; $(B, D) \times 400$. The probe that was used to detect lysozyme $M$ is that of lysozyme $P$, because the mRNA sequence of both lysozyme genes is almost identical, and both mRNA are detected with the used probe. and human chitotriosidase was further investigated by analysis of the promoter regions. Mouse EST cDNA sequences containing the $5^{\prime}$ untranslated region indicate that the mouse chitotriosidase gene has an extra exon compared with the human gene. This first exon is located at least 7000 bp upstream. The human chitotriosidase promoter is homologous to a region found in mouse intron 1 just upstream of exon 2. In conclusion, the promoter of the mouse chitotriosidase gene differs fundamentally from the human one (Figure 7). This likely explains the noted differences in cell type expression of human and mouse chitotriosidase.

\section{Discussion}

Striking analogies exist between mammalian chitinases and lysozymes. Both classes of enzymes are endoglucosaminidases with a compact globular structure lacking $\mathrm{N}$-linked glycans. Expression of both classes of en- zymes is highly regulated, being restricted to certain cell types. A dual function in defense and polysaccharide processing is envisioned for lysozymes and chitinases. For example, in many animals lysozyme functions as a bacteriolytic enzyme expressed in tissue macrophages, but during evolution of various species it has also been recruited for a nutritional function in the gastrointestinal tract (Dobson et al. 1984; Jolles et al. 1984). The expression in man of chitotriosidase in phagocytes and that of acid-stable AMCase in the gastrointestinal tract is reminiscent of this. Like lysozyme, gastrointestinal chitinases might have a dual function in defense and food processing. Research on lysozyme has provided insight into the mechanisms that allow the evolution of specialized lysozymes, driven by the need of a specific organism. For example, ruminants have duplicated the lysozyme gene to yield about ten copies, of which several are expressed in the gastrointestinal tract. Some of these enzymes have evolved into

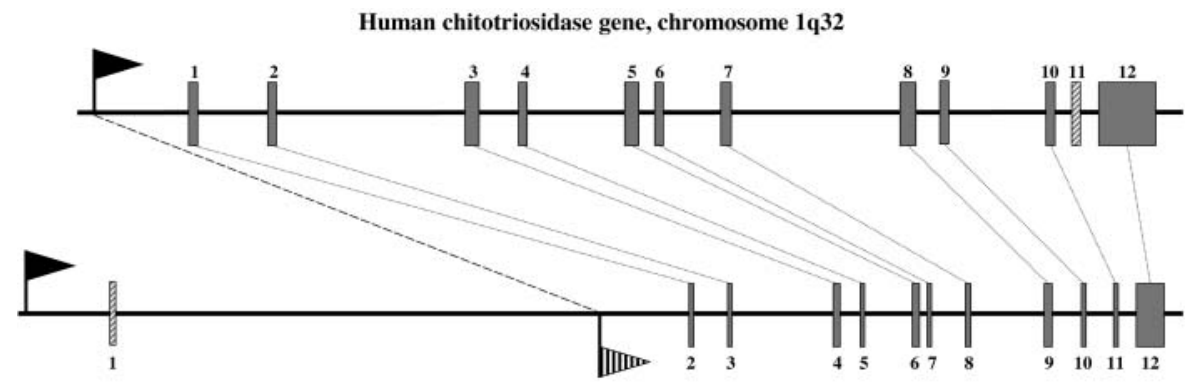

Figure 7 Schematic overview of mouse and human chitotriosidase gene. Homology between mouse and human chitotriosidase exons is indicated with dotted lines. Promoters are indicated with the black flags. The shaded flag indicates the region in mouse intron 1 that is homologous to the human chi-

Mouse chitotriosidase gene, chromosome 1E4 totriosidase promoter. 
extremely acid-stable proteins with an acidic $\mathrm{pH}$ optimum dependent on the site of expression (Irwin 1996; Prager 1996). A very similar process seems to have taken place in the mammalian chitinase family. Duplications have occurred, ultimately leading to specialized chitinases. In the gastrointestinal tract of the mouse, chitotriosidase is produced at sites of near neutral $\mathrm{pH}$ such as the mouth, the non-glandular portion of the stomach, and the small intestine. The expression from the oral cavity to the fore-stomach seems to be restricted to the stratified squamous epithelial cell layer. Chitotriosidase and AMCase activity can be found in the lumen of the gastrointestinal tract, suggesting that these cells secrete the enzyme to the luminal site. However, besides AMCase, considerable chitotriosidase activity can also be found in the circulation. At this time we do not know the exact cellular source of chitotriosidase in the blood. We therefore cannot exclude that a portion of the chitotriosidase produced by the stratified epithelial layer is secreted to the blood. Alternatively, it is possible that another, so far unidentified, cell type is responsible for the chitotriosidase in the circulation.

The acid-stable AMCase is produced predominantly in the glandular portion of the stomach, at the bottom of the gastric glands in chief cells, close to the acidproducing parietal cells, consistent with its features. Stomach lysozymes from ruminants have adapted to function optimally in the hostile acid environment by subtle changes in amino acid composition. The same is also the case for the mouse AMCase that has also adapted to function in the stomach. Analysis of the three-dimensional structure of chitotriosidase and AMCase should reveal the key amino acid substitutions required for the adaptation. The available information on the structure of chitotriosidase should assist further investigations on this matter (Fusetti et al. 2002).

The human AMCase is less well equipped to function in a highly acidic environment compared with the mouse enzyme. Differences in physiology or diet may have contributed to this. Live insects are an important component in the diet of wild mice (Landry 1970).

Intriguingly, in the cow AMCase is produced and secreted by the liver and is present in large amounts in serum (Suzuki et al. 2001). The function of the enzyme is unclear. It seems likely that expression is driven by yet another type of promoter, adding to the rapidly growing complexity of the mammalian chitinase protein family.

Overexpression of chitinases occurs in a number of pathologies in mouse and man. Chitotriosidase is the dominant chitinase in man that is highly expressed in specific cell types including tissue macrophages. In various disorders in which activated macrophages are implicated, elevated plasma chitotriosidase levels occur, e.g., lysosomal lipid storage disorders, sarcoidosis, vis- ceral Leishmaniasis, extended atherosclerosis such as Tangier disease, and thalassemia (Hollak et al. 1994; Barone et al. 1999; Boot et al. 1999; Grosso et al. 2004). In sharp contrast, in mice, expression of chitotriosidase is confined to the gastrointestinal tract and AMCase seems to be the sole endogenous chitinase in tissues such as lung. These species differences seem to be due to distinct promoters of the chitotriosidase genes in mouse and man. The mouse chitotriosidase transcription start site is located far upstream compared with the human situation because the mouse gene contains an extra exon at the $5^{\prime}$ end. Homology is noted between the human promoter and a region in intron 1 of the mouse gene, just upstream of the second exon. Whether this region can indeed act as an alternative promoter for the mouse chitotriosidase gene is at present not known and a topic of further investigation.

The promoter regions of the mouse and human AMCase genes are relatively comparable.

In contrast to Suzuki and coworkers (2002), we were able to detect AMCase mRNA in murine lung with ISH, confirming our Northern blot analysis (Boot et al. 2001). This discrepancy might be due to differences in mice strains or to the sensitivity of the ISH methods. The expression of AMCase mRNA is found to be induced in the lung of mice under various pathological conditions, most strikingly in Th2-driven asthma models (Sandler et al. 2003; Xu et al. 2003; Zhu et al. 2004; Zimmermann et al. 2004). Prominently increased expression of AMCase has also been observed in lung biopsies from asthmatic patients (Zhu et al. 2004).

A surprising role has recently been ascribed to chitinases in the pathogenesis of asthma. It was found that inhibition of chitinase activity in lungs of asthmatic mice alleviates the inflammatory pathology (Zhu et al. 2004). This opens a potential new avenue for therapeutic intervention, i.e., the use of specific chitinase inhibitors such as allosamidin (Zhu et al. 2004). However, extrapolation of the findings with mice to man is complicated by the fact that it is presently unclear whether in addition to AMCase, chitotriosidase is also overexpressed in lung of asthmatic patients. It has been shown that in sarcoidosis, a systemic granulomatous disease, chitotriosidase is elevated in plasma and bronchoalveolar lavage (Hollak et al. 1994; Grosso et al. 2004). It is therefore unclear whether inhibition of both AMCase and chitotriosidase would be required for intervention in the inflammatory process in lungs of asthmatic patients. It may also be possible that selective inhibition of AMCase is more desirable. In this regard, it will be of interest to study whether the relatively common chitotriosidase deficiency influences the clinical course of asthma.

In conclusion, the remarkable differences in cell type and tissue-specific expression of chitotriosidase in man and mouse seem to be mediated by usage of dif- 
ferent promoter regions, gene duplications, and different environmental pressures during the evolution of these different species. Further research is required regarding the physiological functions of the chitinase and their potentially harmful role in excessive inflammatory responses.

\section{Acknowledgments}

We would like to acknowledge Wilma Donker-Koopman, Roelof Ottenhoff, and Anneke Strijland for their skillful technical assistance. Ans Groener and Marco van Eijk are acknowledged for their helpful comments and suggestions during the preparation of the manuscript.

\section{Literature Cited}

Barone R, Di Gregorio F, Romeo MA, Schiliro G, Pavone L (1999) Plasma chitotriosidase activity in patients with beta-thalassemia. Blood Cells Mol Dis 25:1-8

Boot RG, Blommaart EF, Swart E, Ghauharali-van der Vlugt K, Bijl N, Moe C, Place A, et al. (2001) Identification of a novel acidic mammalian chitinase distinct from chitotriosidase. J Biol Chem 276:6770-6778

Boot RG, Renkema GH, Strijland A, van Zonneveld AJ, Aerts JMFG (1995) Cloning of a cDNA encoding chitotriosidase, a human chitinase produced by macrophages. J Biol Chem 270: 26252-26256

Boot RG, Renkema GH, Verhoek M, Strijland A, Bliek J, de Meulemeester TM, Mannens MM, et al. (1998) The human chitotriosidase gene. Nature of inherited enzyme deficiency. J Biol Chem 273:25680-25685

Boot RG, van Achterberg TA, van Aken BE, Renkema GH, Jacobs MJ, Aerts JM, de Vries CJ (1999) Strong induction of members of the chitinase family of proteins in atherosclerosis: chitotriosidase and human cartilage gp-39 expressed in lesion macrophages. Arterioscler Thromb Vasc Biol 19:687-694

Boussac M, Garin J (2000) Calcium-dependent secretion in human neutrophils: a proteomic approach. Electrophoresis 21:665-672

Choi EH, Zimmerman PA, Foster CB, Zhu S, Kumaraswami V, Nutman TB, Chanock SJ (2001) Genetic polymorphisms in molecules of innate immunity and susceptibility to infection with Wuchereria bancrofti in South India. Genes Immun 2:248-253

Couzin J (2004) Immunology. Unexpectedly, ancient molecule tied to asthma. Science 304:1577

Dobson DE, Prager EM, Wilson AC (1984) Stomach lysozymes of ruminants. I. Distribution and catalytic properties. J Biol Chem 259:11607-11616

Fusetti F, von Moeller H, Houston D, Rozeboom HJ, Dijkstra BW, Boot RG, Aerts JM, et al. (2002) Structure of human chitotriosidase. Implications for specific inhibitor design and function of mammalian chitinase-like lectins. J Biol Chem 277:25537-25544

Goto M, Fujimoto W, Nio J, Iwanaga T, Kawasaki T (2003) Immunohistochemical demonstration of acidic mammalian chitinase in the mouse salivary gland and gastric mucosa. Arch Oral Biol 48: 701-707

Grosso S, Margollicci MA, Bargagli E, Buccoliero QR, Perrone A, Galimberti D, Morgese G, et al. (2004) Serum levels of chitotriosidase as a marker of disease activity and clinical stage in sarcoidosis. Scand J Clin Lab Invest 64:57-62

Hollak CEM, van Weely S, van Oers MHJ, Aerts JMFG (1994) Marked elevation of plasma chitotriosidase activity. A novel hallmark of Gaucher disease. J Clin Invest 93:1288-1292

Irwin DM (1996) Molecular evolution of ruminant lysozymes. EXS 75:347-361

Jin HM, Copeland NG, Gilbert DJ, Jenkins NA, Kirkpatrick RB, Rosenberg M (1998) Genetic characterization of the murine Ym1 gene and identification of a cluster of highly homologous genes. Genomics 54:316-322
Jolles P, Schoentgen F, Jolles J, Dobson DE, Prager EM, Wilson AC (1984) Stomach lysozymes of ruminants. II. Amino acid sequence of cow lysozyme 2 and immunological comparisons with other lysozymes. J Biol Chem 259:11617-11625

Landry SO Jr (1970) The rodentia as omnivores. Q Rev Biol 45: $351-372$

Moorman AF, De Boer PA, Ruijter JM, Hagoort J, Franco D, Lamers WH (2000) Radio-isotopic in situ hybridization on tissue sections. Practical aspects and quantification. Methods Mol Biol 137:97-115

Moorman AF, Houweling AC, de Boer PA, Christoffels VM (2001) Sensitive nonradioactive detection of mRNA in tissue sections: novel application of the whole-mount in situ hybridization protocol. J Histochem Cytochem 49:1-8

Prager EM (1996) Adaptive evolution of lysozyme: changes in amino acid sequence, regulation of expression and gene number. EXS 75:323-345

Renkema GH, Boot RG, Au FL, Donker-Koopman WE, Strijland A, Muijsers AO, Hrebicek M, et al. (1998) Chitotriosidase, a chitinase, and the 39-kDa human cartilage glycoprotein, a chitin-binding lectin, are homologues of family 18 glycosyl hydrolases secreted by human macrophages. Eur J Biochem 251:504-509

Renkema GH, Boot RG, Muijsers AO, Donker-Koopman WE, Aerts JMFG (1995) Purification and characterization of human chitotriosidase, a novel member of the chitinase family of proteins. J Biol Chem 270:2198-2202

Renkema GH, Boot RG, Strijland A, Donker-Koopman WE, van den Berg M, Muijsers AO, Aerts JMFG (1997) Synthesis, sorting, and processing into distinct isoforms of human macrophage chitotriosidase. Eur J Biochem 244:279-285

Sahai AS, Manocha MS (1993) Chitinases of fungi and plants: their involvement in morphogenesis and host-parasite interaction. FEMS Microbiol Rev 11:317-338

Saitou N, Nei M (1987) The neighbor-joining method: a new method for reconstructing phylogenetic trees. Mol Biol Evol 4:406-425

Sandler NG, Mentink-Kane MM, Cheever AW, Wynn TA (2003) Global gene expression profiles during acute pathogen-induced pulmonary inflammation reveal divergent roles for Th1 and Th2 responses in tissue repair. J Immunol 171:3655-3667

Schlumbaum A, Mauch F, Vogeli U, Boller T (1986) Plant chitinases are potent inhibitors of fungal growth. Nature 324:365367

Stevens DA, Brammer HA, Meyer DW, Steiner BH (2000) Recombinant human chitinase. Curr Opin Anti-Infective Investig Drugs 2:399-404

Suzuki M, Fujimoto W, Goto M, Morimatsu M, Syuto B, Iwanaga $\mathrm{T}$ (2002) Cellular expression of gut chitinase mRNA in the gastrointestinal tract of mice and chickens. J Histochem Cytochem 50:1081-1089

Suzuki M, Morimatsu M, Yamashita T, Iwanaga T, Syuto B (2001) A novel serum chitinase that is expressed in bovine liver. FEBS Lett 506:127-130

Thompson JD, Gibson TJ, Plewniak F, Jeanmougin F, Higgins DG (1997) The CLUSTAL_X windows interface: flexible strategies for multiple sequence alignment aided by quality analysis tools. Nucleic Acids Res 25:4876-4882

Tjoelker LW, Gosting L, Frey S, Hunter CL, Trong HL, Steiner B, Brammer H, et al. (2000) Structural and functional definition of the human chitinase chitin-binding domain. J Biol Chem 275: 514-520

Xu Y, Clark JC, Aronow BJ, Dey CR, Liu C, Wooldridge JL, Whitsett JA (2003) Transcriptional adaptation to cystic fibrosis transmembrane conductance regulator deficiency. J Biol Chem 278: 7674-7682

Zhu Z, Zheng T, Homer RJ, Kim YK, Chen NY, Cohn L, Hamid Q, et al. (2004) Acidic mammalian chitinase in asthmatic Th2 inflammation and IL-13 pathway activation. Science 304:1678-1681

Zimmermann N, Mishra A, King NE, Fulkerson PC, Doepker MP, Nikolaidis NM, Kindinger LE, et al. (2004) Transcript signatures in experimental asthma: identification of STAT6-dependent and -independent pathways. J Immunol 172:1815-1824 